\title{
Improvement of Visual Field Following Trabeculectomy for Open Angle Glaucoma
}

\author{
EROL YILDIRIM, AHMED H. BILGE, SAMI ILKER \\ Ankara, Turkey
}

\begin{abstract}
Summary
Trabeculectomy was performed in 24 eyes affected by primary open angle glaucoma. Visual fields were measured using automated perimetry preoperatively and in the first, third, sixth and twelfth months after surgery. Significant improvement in visual field occurred in $96 \%$ of cases.
\end{abstract}

The reduction in visual field and the vertical loss of vision in glaucoma is associated with damage to the nerve fibres at the optic disc and has been widely regarded as irreversible. ${ }^{1,2}$ Certainly loss of visual fields is the most important indication for surgery in glaucoma and this field loss can perhaps be best demonstrated by the use of automated perimetry. ${ }^{3}$

It is important to know whether glaucomatous field defect can be improved after trabeculectomy for open angle glaucoma. In this study we have used automated perimetry to evaluate these changes.

\section{Materials and Methods}

Twenty four eyes in 22 patients who were affected by open angle glaucoma and who underwent trabeculectomy in the Gulhane Military Medical Academy and School of Medicine since 1985 are included in this study. No patient suffered any other preoperative cause for loss of vision.

Intra-ocular tensions were measured using the Haag-Streit applanation tonometer. Visual fields were determined using the Synemed-50 computerised perimeter.

Background illumination was standardised at 31.5 asb and measurements were made with refractive errors corrected by adding glasses into the glass-holder in front of the patients eye, and intraocular pressures normalised by medication (acetazolamide and mannitol), and pupil size normalised by stopping pilocarpine and adding phenylephrine $10 \%$ if necessary.

Visual field observations were repeated at one, three, six and twelve months after surgery. Threshold values were calculated for both the whole and the central $30^{\circ}$ of the field.

\section{Results}

Of 22 patients with primary open angle glaucoma, seven were female and 15 were male.

The youngest patient was 20 years old, while the oldest was 80 years (mean age 57.5). The mean value of preoperative intraocular pressure of 24 eyes was $33.79 \mathrm{~F} 8.48 \mathrm{mmHg}$. This value was found to be $15.16 \mathrm{~F} 4.08$ postoperatively. The difference between these values is $18.63 \mathrm{~F} 9.21$ which is statistically significant.

The visions of the patients had the median value of $0.75 \mathrm{~F} 0.28$ preoperatively and $0.79 \mathrm{~F}$ 0.36 postoperatively with Snellen charts. In eight patients $(33 \%)$ the vision improved, whereas in ten $(42 \%)$ deterioration was detected, whilst in $25 \%$ no change was observed. In seven of the ten patients whose visual acuity diminished, mild opacification in the lens was observed on periodical examinations. 
Table I Preoperative and Postoperative Mean Threshold Values of Central and Whole Visual Fields

\begin{tabular}{|c|c|c|}
\hline & CVT (dB) & WTV (dB) \\
\hline Preoperative & 1016.08 F 616.26 & 1206.33 F 746.98 \\
\hline Postoperative 1st Month & 1174.79 F 656.67 & 1328.46 F 756.38 \\
\hline 3rd Month & 1313.58 F 681.56 & 1531.16 F 819.75 \\
\hline 6th Month & 1347.63 F 751.85 & 1580.13 F 837.52 \\
\hline 12th Month & 1417.71 F 805.25 & 1713.96 F 939.91 \\
\hline \multicolumn{3}{|l|}{ The difference between } \\
\hline \multicolumn{3}{|l|}{ Preoperative \& Postoperative } \\
\hline 12 th month & 301.63 & 507.63 \\
\hline
\end{tabular}

The median total threshold values of the patients for the central $30^{\circ}$ (CTV) and the whole visual field (WTV) measured preoperatively and in the first, third, sixth and twelfth postoperative months are shown in Table I.

Analysing the values of CTV in the first postoperative month, it is observed that an improvement in $75 \%$ of the cases occurred. Considering WTV improvement and deterioration, rates were $62.5 \%$ and $37.5 \%$ respectively.

In the third postoperative month, CTV increased in 23 cases $(96 \%)$ and remained unchanged in one $(4 \%)$, whereas WTV increased in $19(79 \%)$ and decreased in five cases $(21 \%)$.

In the sixth month following the operation an increase in the value of CTV was observed in $21(87.5 \%)$ and a decrease in two cases $(12.5 \%)$. WTV values were increased in 22 $(92 \%)$ and decreased in two $(8 \%)$.

In the twelfth month there were 23 cases in which both CTV and WTV values were increased $(96 \%)$ and one case showed a decrease.

The increases observed both in CTV and WTV were found to be statistically significant using the t-test, at each step (Table II).

The increase in CTV and visual improvement exhibited a correlation such that a visual improvement of 0.1 degree equalled an increase in CTV of $121.803 \mathrm{db}$. This correlation was also found to be significant (F-4.30).

\section{Discussion}

It is believed that nerve fibre damage and visual field loss in glaucoma is due to impaired axoplasmic flow and early indications of cell death are provided by changes seen on electron microscopy. ${ }^{4}$ At least $50 \%$ loss of nerve fibres are estimated to be needed before any functional loss can be demonstrated using the Goldmann perimeter. ${ }^{5,4}$

Some observers believe that changes in nerve fibre appearance may be seen long before any alteration in field can be measured. ${ }^{6,7}$ Others have monitored changes in the appearance of the optic disc using stereophotogrammetry, ${ }^{8-11,1}$ stereochronoscopy, ${ }^{11-13}$ and colorimetric measurements. ${ }^{14,15}$ Measurements of colour vision have also been suggested. ${ }^{16-22}$ All these methods however are difficult to use as objective criteria of the functional changes in glaucoma.

Winnie and others have stated that at least two weeks of raised intraocular pressure are required before histopathological changes can be seen in retinal gangion cells. ${ }^{23}$ Within the following week visual cells become lost and other nuclear cell death is seen. Cytochrome oxidase activity in neuroretina and pigment epithelium was decreased before any histological change in the retina could be found. Perhaps the most interesting finding of these observers was that the pigment epithelium uptake was augmented with increased intraocular pressure and the histological changes in the neuroretina followed later.

Chandler, ${ }^{24}$ Kolker $^{25}$ and Quigley and Maumenee $^{26}$ appear to support the idea that pressure reduction in glaucoma patients invariably prevents the long-term progression of visual field defects. Holmin and Bauer have

Table II Statistical Analysis of Visual Field Values (t-test)

\begin{tabular}{lll}
\hline & CTV $(\mathrm{dB})$ & WTV $(\mathrm{dB})$ \\
\hline Preop-1st Month & $3.189>2.07$ & $2.398>2.07$ \\
1st-3rd Month & $2.45>2.07$ & $2.29>2.07$ \\
3rd-6th Month & $2.34>2.07$ & $2.27>2.07$ \\
6th-12th Month & $3.13>2.07$ & $3.30>2.07$ \\
\hline
\end{tabular}


shown that the visual fields of glaucomatous patients after laser trabeculoplasty improved slowly in short-term follow-up. ${ }^{30}$

Others have shown that eyes continued to lose field postoperatively despite satisfactory pressure measurements. ${ }^{27-29}$ In these studies the visual field has been measured with the Goldmann perimeter. We believe that our study is the first to demonstrate function as a threshold value of the whole of the visual field.

One of the most interesting findings in this study was that whole threshold values in cases of open angle glaucoma showed an increase of $507 \mathrm{db}$ within 12 months of surgery. This is difficult to explain when the mean visual acuity remains the same. It is possible that the metabolic events reported by Winnie and others may explain the slow improvement of visual field many months after reduction of intraocular pressure following trabeculectomy surgery.

\section{References}

${ }^{1}$ Sears ML: Clinical and scientific basis for the management of open angle glaucoma. Arch Ophthalmol 1986, 104: 191-5.

${ }^{2}$ Drance SM, Douglas GR, Airaksinen PJ, Schulzer M, Hitchings RA. Diffuse visual field loss in chronic open-angle and low-tension glaucoma. Am J Ophthalmol 104: 577-80.

${ }^{3}$ Johnson CA and Keltner JL: Automated suprathreshold static perimetry. Am J Ophthalmol 1980, 89: 734-41.

${ }^{4}$ Quigley HA, Addicks EM, Green WR, Maumenee AE. Optic nerve damage in human glaucoma II. The site of injury and susceptibility of damage. Arch Ophthalmol 1985, 99: 635-40.

${ }^{5}$ Quigley HA, Lewis RA, Johnson CA: Early detection of glaucomatous damage. I. Psychophysical disturbances II. Changes in the appearance of optic disc. Surv Ophthalmol 1985, 30(2): 111-26.

${ }^{6}$ Sommer A, Miller NR, Pollack I. et al: The nerve fibre layer in the diagnosis of glaucoma. Arch Ophthalmol 1977, 95: 2149-56.

${ }^{7}$ Sommer A, Pollack I, Maumenee AE: Optic disc parameters and onset of glaucomatous field loss. II. Static screening criterio. Arch Ophthalmol 1979, 97: 1449-54.

${ }^{8}$ Johnson CA, Keltner JL, Krohn MA, Portnen GL: Photogrammetry of the optic disc in glaucoma and ocular hypertension with simultaneous stereo-photography. Invest Ophthalmol Vis Sci 1979, 18: 1252-63.

${ }^{9}$ Kottler MS, Rosenthal AR, Falconer DG: Analog vs digital photogrammetry for optic cup analysis. Invest Ophthalmol Vis Sci 1976, 15: 651-4.

${ }^{10}$ Krohn MA, Keltner JL, Johnson CA: Comparison of photographic techniques and films used in stereo photogrammetry of the optic disc. Am J Ophthalmol 1976, 88: 859-63.

${ }^{11}$ Schirmer KE: Simplified photogrammetry of the optic disc. Arch Ophthalmol 1976, 94: 1997-2001.

${ }^{12}$ Schirmer KE, Kratky V: Stereochronoscopy of the optic disc with stereoscopic cameras. Arch Ophthalmol 1980, 90: 1647-9.

${ }^{13}$ Schwartz B: New techniques for the examination of the optic disc and their clinical application. Trans Am Acad Ophthalmol Otolaryngol 1976, 81: 227-35.

${ }^{14}$ Davies EWG: Quantitative assessment of colour of the optic disc by a photographic method. Exp Eye Res 1970, 9: 106-13.

${ }^{15}$ Gloster J: The colour of the optic disc. Doc Ophthalmol Proc Series 1969, 26: 155-63.

${ }^{16}$ Berkowitz JS and Balter S: Colorimetric measurements of the optic disc. Am J Ophthalmol 1970, 69: $385-6$.

${ }^{17}$ Drance SM: Early disturbances of colour vision in chronic open angle glaucoma. Doc Ophthalmol Proc Series 1981, 20: 155-9.

${ }^{18}$ Drance SM, Lakowski R, Schulzer M, Douglas GR: Acquired colour vision changes in glaucoma. Use of 100 Hue test and Pickford anomaloscope predictors of glaucomatous field change. Arch Ophthalmol 1984, 99: 38-9.

${ }^{19}$ Flammer J and Drance SM: Correlation between colour vision scores and quantitative perimetry in suspected glaucoma. Arch Ophthalmol 1984, 102: 38-9.

${ }^{20}$ Hamill TR, Post RB, Johnson CA, Keltner JL: Correlation of color vision deficits and observable changes in the optic disc in population of ocular hypertensives. Arch Ophthalmol 1984, 102: 1637-9.

${ }^{21}$ Hart WM, Hartz RK, Hagen RW, Clarc KW: Color contrast perimetry. Invest Ophthalmol Vis Sci 1984, 25: 400-13.

${ }^{22}$ Regan DM and Neima D: Balance between pattern flicker sensitivities in the visual fields of an ophthalmological patient. Br J Ophthalmol 1984, 68: $310-15$.

${ }^{23}$ Winnie WY, Li, Corrinna YW and Davia T. Yew responses of the pigment epithelium and the neuroretina after intraocular pressure increase. Cell Molecul Biol 1986, 104: 191-5

${ }^{24}$ Chandler PA: Long-term results in glaucoma therapy. Am J Ophthalmol 1960, 40: 221-46.

${ }^{25}$ Kolker AE: Visual prognosis in advanced glaucoma: A comparison of medical and surgical therapy for retention of vision in 101 eyes with advanced glaucoma. Trans Am Ophthalmol Soc 1977, 75: 539-55.

${ }^{26}$ Quigley HA and Maumenee AE: Long term follow-up of treated open angle glaucoma. Am J Ophthalmol 1979, 87: 519-25.

${ }^{27}$ Kidd NM, O'Connor M: Progression of field loss 
after trabeculectomy: a five year follow-up. $\mathrm{Br} J$ Ophthalmol 1985, 69: 827-31.

${ }^{28}$ Rollins DF and Drance SM: Five years follow-up trabeculectomy in the management of chronic open angle glaucoma. Symposium on glaucoma. Trans New Orleans Acad Ophthalmol St Louis: Mosby, 1981, 295-300.
${ }^{29}$ Werner EB, Drance M, Schulzer M: Trabeculectomy and the progression of glaucomatous visual field loss. Arch Ophthalmol 1977, 95: 1374-7.

${ }^{30}$ Holmm C and Bauer B: Laser trabeculoplasty in open angle glaucoma. A short term study using computerised perimetry. Acta Ophthalmol 1984, 62: $337-41$. 